\title{
Prognostic significance of CTNNB1 mutation in early stage endometrial carcinoma: a systematic review and meta-analysis
}

\author{
Antonio Travaglino' ${ }^{1}$ Antonio Raffone ${ }^{2,3}\left[\right.$ Diego Raimondo $^{3} \cdot$ Sabrina Reppuccia $^{2} \cdot$ Alessandro Ruggiero $^{2}$. \\ Alessandro Arena ${ }^{3} \cdot$ Paolo Casadio $^{3} \cdot$ Fulvio Zullo $^{2} \cdot$ Luigi Insabato $^{1} \cdot$ Renato Seracchioli $^{3} \cdot$ Antonio Mollo $^{4}$
}

Received: 24 February 2021 / Accepted: 20 December 2021 / Published online: 16 January 2022

(c) The Author(s) 2022

\begin{abstract}
Background In the last years, mutations in the exon 3 of CTNNB1 have emerged as a possible prognostic factor for recurrence in early stage endometrioid endometrial carcinoma, especially in cases with no specific molecular profile (NSMP).

Objective To define the prognostic value of CTNNB1 mutations in early stage endometrioid endometrial carcinoma, through a systematic review and meta-analysis.

Methods Electronic databases were searched from their inception to November 2020 for all studies assessing the prognostic value of $C T N N B 1$ mutation in early stage (FIGO I-II) endometrioid endometrial carcinoma. Odds ratio (OR) for tumor recurrence and hazard ratio (HR) for disease-free survival (DFS) were calculated with a significant $p$ value $<0.05$.

Results Seven studies with 1031 patients were included. Four studies were suitable for meta-analysis of OR and showed significant association between $C T N N B 1$ mutation and the absolute number of recurrence $(\mathrm{OR}=3.000 ; p=0.019)$; the association became stronger after excluding patients with known molecular status other than NSMP $(\mathrm{HR}=5.953 ; p=0.012)$. Three studies were suitable for meta-analysis of HR and showed no significant association between CTNNB1 mutation and decreased DFS (HR $=1.847 ; p=0.303)$; the association became significant after excluding patients with known molecular status other than NSMP $(\mathrm{HR}=2.831 ; p=0.026)$.

Conclusion $C T N N B 1$ mutation is significantly associated with recurrence in early stage endometrioid endometrial carcinomas, especially in the NSMP, appearing potentially useful in directing adjuvant treatment.
\end{abstract}

Keywords $\beta$-Catenin $\cdot$ CTNNB1 $\cdot$ Endometrioid $\cdot$ Adjuvant treatment $\cdot$ Risk group

Renato Seracchioli and Antonio Mollo equally contributed to the study and shared the last authorship.

Antonio Raffone

anton.raffone@gmail.com; antonio.raffone2@unibo.it

$\triangle$ Renato Seracchioli

renato.seracchioli@unibo.it

1 Anatomic Pathology Unit, Department of Advanced Biomedical Sciences, School of Medicine, University of Naples Federico II, Naples, Italy

2 Gynecology and Obstetrics Unit, Department of Neuroscience, Reproductive Sciences and Dentistry, School of Medicine, University of Naples Federico II, Via Sergio Pansini, 5, 80131 Naples, Italy
3 Division of Gynaecology and Human Reproduction Physiopathology, Department of Medical and Surgical Sciences (DIMEC), IRCCS Azienda Ospedaliero-Univeristaria di Bologna. S. Orsola Hospital, University of Bologna, Via Massarenti 13, 40138 Bologna, Italy

4 Gynecology and Obstetrics Unit, Department of Medicine, Surgery and Dentistry "Schola Medica Salernitana", University of Salerno, 84081 Baronissi, Italy 


\section{Introduction}

Endometrial carcinoma (EC) is the most common gynecological malignancy in the western countries $[1,2]$. The current European system for the prognostic stratification of EC is based on International Federation of Gynecology and Obstetrics (FIGO) stage and grade, histotype and lymphovascular space invasion (LVSI). Such system subdivides early stage EC (i.e., limited to the uterus) into 4 risk categories: low risk (FIGO IA G1-2 endometrioid with no substantial LVSI), intermediate risk (FIGO IB G1-2 endometrioid with no substantial LVSI; FIGO IA G3 endometrioid with no substantial LVSI; FIGO IA non-endometrioid without myometrial invasion), high-intermediate risk (Stage IA-B G1-2 endometrioid with LVSI; FIGO IB G3 endometrioid; FIGO II), high risk (FIGO III-IVA with no residual disease; FIGO I-IVA non-endometrioid with myometrial invasion and no residual disease) [3]. Such system can be integrated with the molecular classifier proposed by The Cancer Genome Atlas (TCGA), which identifies four prognostic groups: ultramutated/polymerase- $\varepsilon$ (POLE) -mutant, hypermutated/microsatellite-instable, copy-number-low/no specific molecular profile (NSMP), and copy-number-high/TP53-mutant [4]. In fact, POLEmutant ECs up to FIGO stage II are considered at low risk, while TP53-mutant endometrioid ECs are lumped together with non-endometrioid ECs; the other two TCGA groups are considered at intermediate prognosis and do not alter the risk category [3]. The main role of such stratification system is to guide adjuvant treatment. In fact, based on the risk category, patients may undergo observation alone, vaginal brachytherapy, external beam radiotherapy and/or chemotherapy [3].

However, the NSMP groups (which is the most represented TCGA group) appears to have a highly heterogeneous prognosis, which ranges from good (similar to that of the POLE-mutant group) to poor (similar to that of the TP53-mutant group) [5-10]. The overall good-to-intermediate prognosis is attributable to the high percentage of early stage endometrioid ECs with low-risk histological features within this group [11]. The NSMP group by definition lacks specific molecular signatures and is defined by the exclusion of the other TCGA group [4]. Therefore, the biological behavior of ECs within this group might be affected by other molecular features which are not considered in the TCGA classification. In recent years, several studies proposed that mutations in the exon 3 of $C T N N B 1$ ( $\beta$-catenin-encoding gene) could identify low-grade, early stage endometrioid EC at increased risk of recurrence [12-16]. This would be of paramount importance for the patient management, in terms of choice of appropriate adjuvant treatment. However, other studies did not find the same results $[17,18]$, and most research groups do not take into account the CTNNB1 status for the risk stratification of EC [19, 24].

The aim of this study was to assess the prognostic significance of CTNNB1 mutation in early stage endometrioid EC, through a systematic review and meta-analysis.

\section{Materials and methods}

\section{Study protocol}

Based on previous studies [2, 25], we a priori designed methods for each review stage (electronic search, study selection, data extraction, risk of bias within studies assessment and data analysis), which was independently performed by two authors; disagreements were solved by consensus. This review was reported following the Preferred Reporting Items for Systematic Reviews and Meta-Analyses (PRISMA) guidelines [26].

\section{Search strategy and study selection}

Four electronic databases (Scopus, Web of Sciences, Google Scholar and MEDLINE) were searched from their inception to November 2020 for all studies assessing the prognostic value of $C T N N B 1$ mutations in early stage (FIGO I-II) endometrioid EC. The following combination of text words was used: endometrial AND (cancer OR carcinoma) AND (CTNNB1 OR $\beta$-catenin). Reference lists of relevant studies were also searched. PICO [26] of our study were: "P" $($ population $)=$ patients with early stage $($ FIGO I-II) endometrioid EC; "I" (intervention or risk factor) $=C T N N B 1$ exon 3 mutation; "C" (comparator) $=C T N N B 1$ wild type; "O" (outcome) $=$ tumor recurrence or disease-free survival (DFS). The following exclusion criteria, defined a priori, were adopted: overlapping patient data, sample size $<10$, data not extractable, reviews.

\section{Data extraction}

Data from primary studies were extracted by two independent authors (SR and ARu) without modifications. Extracted data were: sample size, $C T N N B 1$ status and absolute number of recurrence (for the analysis of the absolute risk of recurrence), hazard ration (HR) for recurrence with $95 \%$ confidence interval (CI, for the analysis of DFS), selection criteria (i.e., FIGO grade and stage, histotype), period of enrollment, molecular methods and oncologic outcomes (for the risk of bias assessment); additional extracted data were patient age, body mass index (BMI) and follow-up duration. 


\section{Risk of bias assessment}

As previously described [25, 27], the risk of bias assessment was based on the revised Quality Assessment of Diagnostic Accuracy Studies (QUADAS-2) [28]. Four domains were assessed: (1) Patient selection (correct reporting of selection criteria and period of enrollment); (2) Index test (correct reporting of methods for $C T N N B 1$ mutation analysis); (3) Reference standard (correct reporting of oncologic outcomes); (4) Flow (inclusion of all eligible patients in the analysis). For each domain and in each study, the authors' judgement was "low", "unclear" or "high" risk of bias, as previously described [25, 27].

\section{Data analysis}

For the studies that reported the absolute number of recurrence in $C T N N B$-mutant vs $C T N N B 1$-wild-type cases, odds ratio (OR) was calculated to assess the association between CTNNB1 status and recurrence. For the studies that performed Cox regression survival analysis for DFS, HR of CTNNB1-mutant cases compared to CTNNB1-mutant cases was assessed; only HRs from multivariate analyses (i.e., adjusted for other clinicopathological factors) were assessed. Statistical heterogeneity among studies was calculated using inconsistency index $\left(I^{2}\right)$ as previously described $[2,25]$. A random-effect model was used to pool data. A $p$ value $<0.05$ was considered significant. Results of each study and pooled estimates were reported on forest plots with $95 \%$ CI.

Data analysis was performed using Comprehensive MetaAnalysis (Biostat, 14 North Dean Street, Englewood, NJ 07631, USA).

\section{Results}

\section{Study selection and characteristics}

Seven studies with a total sample size of 1031 patients with early-stage endometrioid EC were included [11-17]. The process of study selection is shown in Fig. 1. Regarding FIGO stage, two studies only included stage IA cases, four studies included stage IA-IB cases and one study included stage I-II cases. Regarding FIGO grade, three studies only included G1 cases, two studies included G1-2 cases and two studies also included selected subset of G3 cases; out of these G3 cases, endometrioid carcinomas with $\geq 50 \%$ myometrial invasion and non-endometrioid carcinomas were not considered. Mean patient age ranged from 57 to 69.6 ; mean BMI ranged from 28 to 34.2 and was not reported in three studies. Mean follow-up duration ranged from 33 to 131 months and was not reported in two studies. Adjuvant treatment included observation alone, vaginal brachytherapy

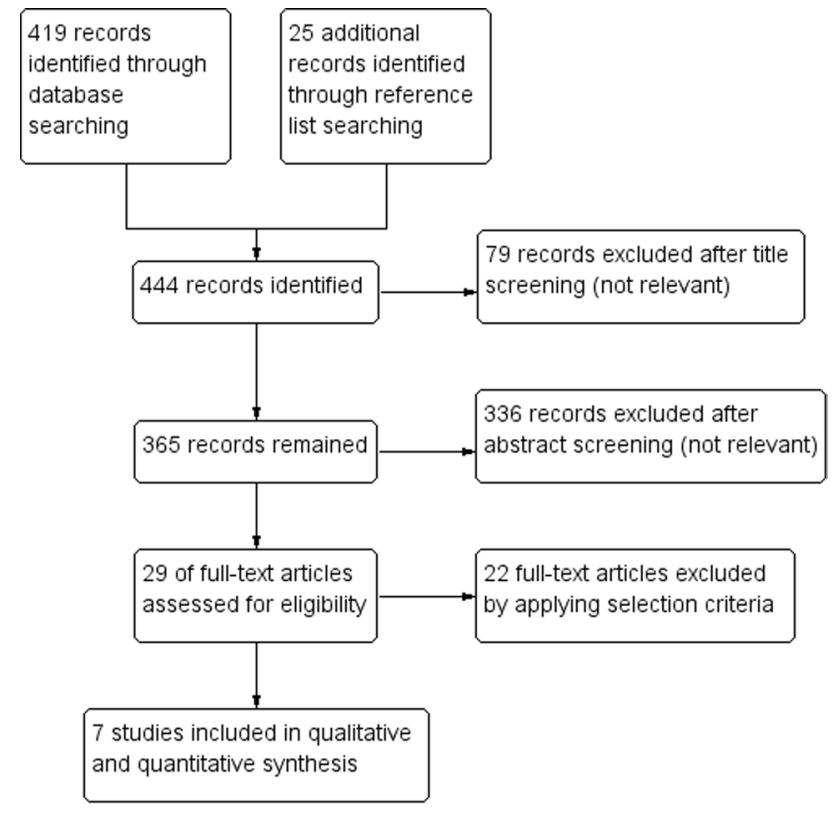

Fig. 1 Flow diagram of studies identified in the systematic review (Prisma template [Preferred Reporting Item for Systematic Reviews and Meta-analyses])

and external beam radiotherapy. Characteristics of the included studies are shown in Table 1.

\section{Risk of bias assessment}

For the "Patient selection" domain, all studies were considered at low risk, since they reported period of enrollment and selection criteria; one study did not specify the period of enrollment but was still considered at low risk, since it assessed the TCGA database. For the "Index test" domain, all studies were considered at low risk, since they specified methods for CTNNB1 assessment. For the "reference standard", unclear risk of bias was assigned to two studies (follow-up data not clearly detailed). For the "flow" domain, two studies were considered at unclear risk, since they assessed CTNNB1 mutations only in a subset of patient; the remaining studies were considered at low risk. Risk of bias assessment results are presented in Fig. 2.

\section{Meta-analysis}

One-hundred and forty-nine patients, all with FIGO stage I, low-grade (G1-2) EC, were assessed for the absolute number of recurrence; the DFS was not assessed in these patients. Overall, 44 patients (22.7\%) recurred; CTNNB1 mutations were detected in 23/44 (52.3\%) recurrent patients and 26/101 (25.7\%) non-recurrent patients. Statistical heterogeneity among studies was low $\left(I^{2}=29.1 \%\right.$, non-significant $)$. 
Table 1 Characteristics of the included studies

\begin{tabular}{|c|c|c|c|c|c|c|c|c|c|}
\hline Study & Country & $\begin{array}{l}\text { Period of } \\
\text { enrollment }\end{array}$ & $\begin{array}{l}\text { Selection } \\
\text { criteria }\end{array}$ & Sample size & $\begin{array}{l}\text { Age, mean/ } \\
\text { median, } \\
\text { years }\end{array}$ & $\begin{array}{l}\text { BMI, mean/ } \\
\text { median, } \mathrm{kg} / \\
\mathrm{m}^{2}\end{array}$ & $\begin{array}{l}\text { Follow- } \\
\text { up, mean/ } \\
\text { median, } \\
\text { months }\end{array}$ & $\begin{array}{l}\text { Adjuvant } \\
\text { treatment } \\
\text { (no.) }\end{array}$ & $\begin{array}{l}\text { Recurrence } \\
\text { (no.) }\end{array}$ \\
\hline Myers 2014 & USA & 1998-2010 & $\begin{array}{l}\text { FIGO IA G1 } \\
\text { EC }\end{array}$ & 47 & $\begin{array}{l}69.6 \text { (cases) } \\
62.8 \text { (con- } \\
\text { trols) }\end{array}$ & $\begin{array}{l}28 \text { (cases) } \\
34 \text { (con- } \\
\text { trols) }\end{array}$ & $\begin{array}{l}62 \text { (cases) } \\
124 \text { (con- } \\
\text { trols) }\end{array}$ & $\begin{array}{l}\text { None (46), } \\
\text { brachy- } \\
\text { therapy } \\
(1)\end{array}$ & 11 \\
\hline Stelloo 2016 & Netherlands & $\begin{array}{c}1990-1997 \\
2000-2006\end{array}$ & $\begin{array}{l}\text { FIGO IB } \\
\text { G1-2 EC, } \\
\text { FIGO IA } \\
\text { G3 EC }\end{array}$ & $\begin{array}{l}546(443 \\
\text { were } \\
\text { NSMP) }\end{array}$ & 68 & Not reported & 131 & $\begin{array}{l}\text { None }(241), \\
\text { brachy- } \\
\text { therapy } \\
(184), \\
\text { EBRT } \\
(409)\end{array}$ & $\begin{array}{l}23 \text { (only } \\
\text { distant) }\end{array}$ \\
\hline Kurnit 2017 & USA & 2000-2015 & $\begin{array}{l}\text { FIGO I-II } \\
\text { G1-2 EC }\end{array}$ & 125 & 60.6 & 33.8 & Not reported & Not reported & Not reported \\
\hline $\begin{array}{l}\text { Imboden } \\
2019\end{array}$ & Switzerland & 2002-2014 & $\begin{array}{l}\text { FIGO I } \\
\text { G1-2 EC }\end{array}$ & $\begin{array}{l}41 \text { (18 } \\
\text { tested for } \\
\text { CTNNB1) }\end{array}$ & 67.8 & Not reported & $\begin{array}{l}38.6 \text { (cases) } \\
93.5 \text { (con- } \\
\text { trols) }\end{array}$ & $\begin{array}{c}\text { None (2), } \\
\text { brachy- } \\
\text { therapy } \\
(16)\end{array}$ & 9 \\
\hline $\begin{array}{l}\text { Moroney } \\
2019\end{array}$ & USA & 2007-2017 & $\begin{array}{l}\text { FIGO I G1 } \\
\text { EC }\end{array}$ & 44 & $\begin{array}{l}57 \text { (cases) } \\
59 \text { (controls) }\end{array}$ & $\begin{array}{l}33.1 \text { (cases) } \\
34.2 \text { (con- } \\
\text { trols) }\end{array}$ & $\geq 86$ months & None & 15 \\
\hline Li 2020 & China & $\begin{array}{l}\text { Not } \\
\text { reported }^{\mathrm{a}}\end{array}$ & FIGO I $^{\mathrm{b}}$ & $\begin{array}{l}294 \text { (215 } \\
\text { eligible } \\
\text { for meta- } \\
\text { analysis) }\end{array}$ & 64 & Not reported & Not reported & $\begin{array}{l}\text { None (123), } \\
\text { brachy- } \\
\text { therapy } \\
(92), \\
\text { EBRT (79) }\end{array}$ & Not reported \\
\hline $\begin{array}{l}\text { Stasenko } \\
2020\end{array}$ & USA & 2009-2017 & $\begin{array}{l}\text { FIGO IA G1 } \\
\text { EC }\end{array}$ & $\begin{array}{l}486(36 \\
\text { tested for } \\
\text { CTNNB1) }\end{array}$ & 58 & 31 & $\begin{array}{l}51 \text { months } \\
\text { (cases) } \\
33 \text { months } \\
\text { (controls) }\end{array}$ & None & 9 \\
\hline
\end{tabular}

${ }^{a}$ Data are retrieved from the TCGA database

${ }^{\mathrm{b}}$ The group of patients with high-risk features (i.e., G3 endometrioid with $>50 \%$ myometrial invasion and non-endometrioid) was excluded from meta-analysis

Pooled OR was 3.000 (95\% CI 1.194-7.540), indicating a significant association between $C T N N B 1$ mutation and recurrence ( $p=0.019)$ (Fig. 3). The strength of association increased after excluding patients with known molecular status other than NSMP, with a pooled OR of 5.953 (95\% CI 1.470-24.112; $p=0.012$ ) (Fig. 4) and low statistical heterogeneity among studies $\left(I^{2}=41.2 \%\right)$.

Eight-hundred and eighty-six patients were assessed for DFS; these patients also included FIGO stage II and G3 endometrioid EC with $<50 \%$ myometrial invasion. The absolute number of CTNNB1-mutant cases and recurrences was not available for these patients. Molecular status was known for 546/886 (61.6\%) patients. Statistical heterogeneity among studies was high $\left(I^{2}=84.2 \%\right.$, significant). Pooled HR was 1.874 (95\% CI 0.567-6.193), indicating no significant association between CTNNB1 mutation and DFS ( $p=0.303)$ (Fig. 5). After excluding patients with known molecular status other than NSMP, the association between $C T N N B 1$ mutation and decreased DFS became significant, with a pooled HR of 2.831 (95\% CI 1.133-7.077; $p=0.026$ ) (Fig. 6); statistical heterogeneity was moderate $\left(I^{2}=69.4 \%\right.$, significant $)$.

\section{Discussion}

This study showed that $C T N N B 1$ mutation was associated with increased absolute risk of recurrence in early stage endometrioid EC, especially after excluding patients with known molecular status other than NSMP; the association 
with DFS was significant only after excluding patients with known molecular status other than NSMP. To our knowledge, this is the first meta-analysis assessing the prognostic value of CTNNBI mutations in early stage endometrioid EC.

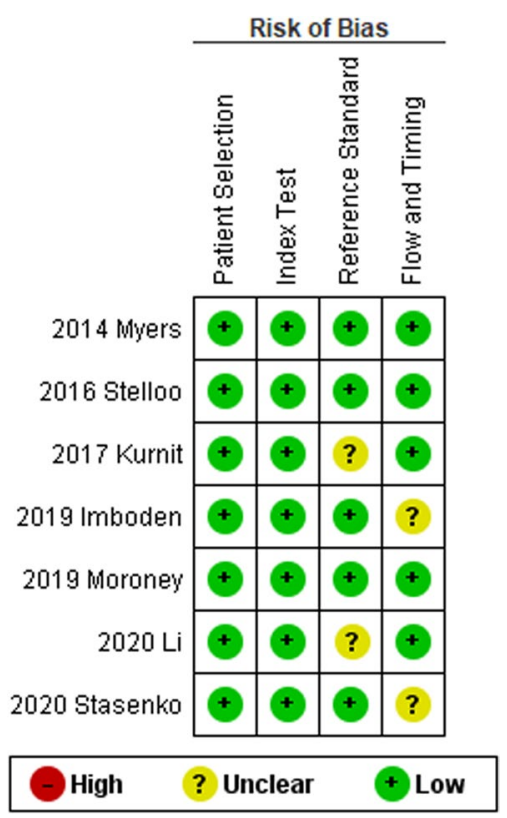

Fig. 2 Assessment of risk of bias. Summary of risk of bias for each study; Plus sign: low risk of bias; minus sign: high risk of bias; question mark: unclear risk of bias

Fig. 3 Forest plot reporting odds ratio (HR) values with $95 \%$ confidence interval $(\mathrm{CI})$, for each study and as pooled estimate, for the association between $C T N N B 1$ mutation and endometrial cancer recurrence

Fig. 4 Forest plot reporting odds ratio (HR) values with 95\% confidence interval $(\mathrm{CI})$, for each study and as pooled estimate, for the association between CTNNB1 mutation and endometrial cancer recurrence, after excluding the cases with known molecular status other than NSMP

\begin{tabular}{cccccc} 
Model & Study name & & \multicolumn{4}{c}{ Statistics for each study } \\
\cline { 3 - 5 } & $\begin{array}{c}\text { Odds } \\
\text { ratio }\end{array}$ & $\begin{array}{c}\text { Lower } \\
\text { limit }\end{array}$ & $\begin{array}{c}\text { Upper } \\
\text { limit }\end{array}$ & p-Value \\
Myers & 9,600 & 1,982 & 46,498 & 0,005 \\
Imboden & 1,000 & 0,156 & 6,420 & 1,000 \\
Moroney & 3,938 & 1,057 & 14,672 & 0,041 \\
Stasenko & 1,600 & 0,343 & 7,457 & 0,549 \\
Random & 3,000 & 1,194 & 7,540 & 0,019
\end{tabular}

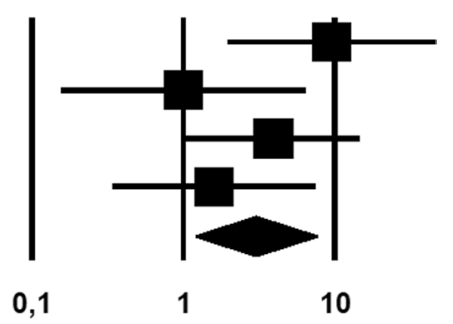

\begin{tabular}{llrlrr} 
Model & Study name & \multicolumn{5}{c}{ Statistics for each study } \\
\cline { 3 - 6 } & & $\begin{array}{c}\text { Odds } \\
\text { ratio }\end{array}$ & $\begin{array}{c}\text { Lower } \\
\text { limit }\end{array}$ & $\begin{array}{c}\text { Upper } \\
\text { limit }\end{array}$ & p-Value \\
Myers & 9,600 & 1,982 & 46,498 & 0,005 \\
Imboden & 1,000 & 0,141 & 7,099 & 1,000 \\
Moroney & 40,385 & 2,009 & 811,906 & 0,016 \\
Stasenko & 6,667 & 0,597 & 74,506 & 0,123 \\
Random & 5,953 & 1,470 & 24,112 & 0,012
\end{tabular}

Odds ratio and $95 \% \mathrm{CI}$
$C T N N B 1$ encodes for $\beta$-catenin, a key protein in the Wnt signaling pathway. In healthy tissues, $\beta$-catenin is normally expressed on the cell membrane, where it links cytoskeleton to cell-cell adherens junctions. As consequence of the Wnt pathway activation, $\beta$-catenin translocates into the nucleus, where it binds to transcription factors that favor cell proliferation. However, the accumulation of $\beta$-catenin into the nucleus may also occur in the case of pathologic alterations of the Wnt pathway, such CTNNB1 mutation. These conditions are associated with carcinogenesis $[29,30]$. In EC, the role of CTNNB1 mutations is well documented, occurring in about 25-30\% of cases. In particular, CTNNB1 mutations are typically found in endometrioid histotype but not in serous histotype and are also observed in endometrioid intraepithelial neoplasia and atypical polypoid adenomyoma, which are regarded as precancerous lesions [4, 29-31].

In 2013, TCGA showed that CTNNB1 mutations were particularly common in the NSMP group (about half of cases) [4]. The value TCGA molecular classification has repeatedly been confirmed in several subsequent studies [18-23]. However, it has also become evident that the NSMP group is too molecularly and prognostically heterogeneous to be clinically consistent. In fact, its prognosis strongly depends on FIGO grade and histotype [5, 10, 32]. The main issue is with early stage, low-grade endometrioid EC; in such subset of patients, identifying the cases at higher risk of recurrence which need adjuvant treatment appears crucial [3]. The Leiden group of the trans-PORTEC initiative

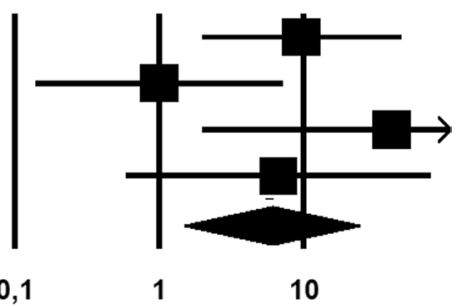


Fig. 5 Forest plot reporting hazard ratio (HR) values with 95\% confidence interval $(\mathrm{CI})$, for each study and as pooled estimate, for the hazard of recurrence in CTNNB1-mutant vs $C T N N B 1$-wild-type endometrial cancer

\begin{tabular}{llllrr} 
Model & Study name & \multicolumn{5}{c}{ Statistics for each study } \\
& $\begin{array}{c}\text { Hazard } \\
\text { ratio }\end{array}$ & $\begin{array}{c}\text { Lower } \\
\text { limit }\end{array}$ & $\begin{array}{c}\text { Upper } \\
\text { limit }\end{array}$ & p-Value \\
Stelloo & 0,934 & 0,453 & 1,927 & 0,853 \\
Kurnit & 5,970 & 2,694 & 13,230 & 0,000 \\
\multicolumn{1}{c}{ Li } & 1,164 & 0,442 & 3,066 & 0,759 \\
Random & 1,874 & 0,567 & 6,193 & 0,303
\end{tabular}

Hazard ratio and $95 \% \mathrm{Cl}$

$\underline{\text { Hazard ratio and } 95 \% \mathrm{Cl}}$

\begin{tabular}{lllllr} 
Model & Study name & \multicolumn{5}{c}{ Statistics for each study } \\
& $\begin{array}{c}\text { Hazard } \\
\text { ratio }\end{array}$ & $\begin{array}{c}\text { Lower } \\
\text { limit }\end{array}$ & $\begin{array}{c}\text { Upper } \\
\text { limit }\end{array}$ & p-Value \\
Stelloo & 2,959 & 1,234 & 7,097 & 0,015 \\
Kurnit & 5,970 & 2,694 & 13,230 & 0,000 \\
\multicolumn{1}{c}{ Li } & 1,164 & 0,442 & 3,066 & 0,759 \\
Random & 2,831 & 1,133 & 7,077 & 0,026
\end{tabular}

Random

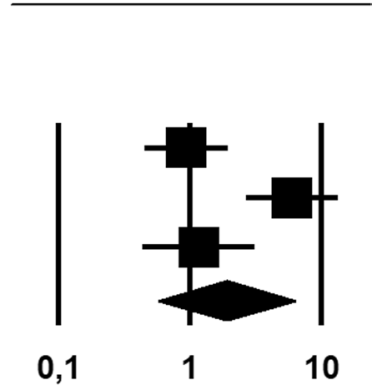

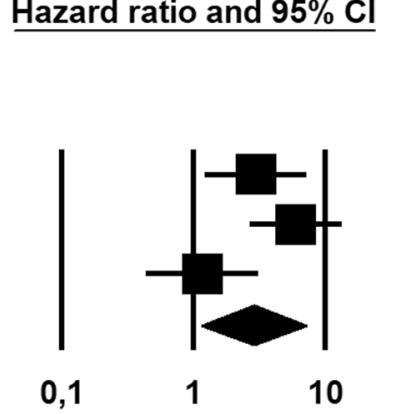

Fig. 6 Forest plot reporting hazard ratio (HR) values with 95\% confidence interval (CI), for each study and as pooled estimate, for the hazard of recurrence in CTNNB1-mutant vs $C T N N B 1$-wild-type endometrial cancer, after excluding the cases with known molecular status other than NSMP

\section{.}


showed different prognostic marker and molecular signatures [43-47]. Since CTNNB1 mutations are also common in ovarian endometrioid carcinoma (even more than in its endometrial counterpart [43]), it cannot be excluded that CTNNB1 status might also be clinically useful in ovarian carcinoma.

Our results have some limitations which should be considered. First, not all studies performed the whole TCGA molecular classification, preventing to draw definitive conclusions about the significance of CTNNB1 mutation in the different TCGA groups. Second, the primary studies selected cases at different FIGO stage (IA, IB, II), and it was, therefore, impossible to define whether the prognostic value of $C T N N B 1$ changed with different stages. Furthermore, other factors, such as the length of follow-up and the treatment adopted, may have affected the final results. We think that further studies in this field should assess the prognostic value of $C T N N B 1$ mutation in large cohorts stratified by both TCGA molecular groups and classical histopathological prognostic parameters (i.e., FIGO stage and grade, histotype, LVSI). Only in this way can the precise prognostic significance and clinical applicability of CTNNB1 be defined.

\section{Conclusion}

The presence of mutations in the exon 3 of $C T N N B 1$ appears as a significant predictor of recurrence in early stage endometroid EC, in particular in the NSMP EC. This finding strengthens the idea that $C T N N B 1$ status might be used to substratify early stage, low-grade EC with NSMP, aiding to identify cases that need adjuvant treatment. Further studies are encouraged to confirm these findings and define their clinical significance in cohorts of patients stratified by TCGA classification.

\footnotetext{
Author contribution AT: project development, protocol development, interpretation, manuscript writing; AR: project development, protocol development, interpretation, manuscript editing; DR: protocol development, interpretation, manuscript writing; SR: data extraction, data analysis, manuscript writing; AR: data extraction, data analysis, manuscript writing; AA: electronic search, study selection, manuscript writing; PC: electronic search, study selection, manuscript writing; RS: risk of bias assessment, manuscript editing, supervision; FZ: protocol development, manuscript writing, supervision; LI: project development, manuscript editing, supervision; AM: risk of bias assessment, manuscript editing, supervision.
}

Funding No financial support was received for this study.

\section{Declarations}

Conflict of interest The authors report no conflict of interest.

Ethical approval Not applicable.

Informed consent Not applicable.

Open Access This article is licensed under a Creative Commons Attribution 4.0 International License, which permits use, sharing, adaptation, distribution and reproduction in any medium or format, as long as you give appropriate credit to the original author(s) and the source, provide a link to the Creative Commons licence, and indicate if changes were made. The images or other third party material in this article are included in the article's Creative Commons licence, unless indicated otherwise in a credit line to the material. If material is not included in the article's Creative Commons licence and your intended use is not permitted by statutory regulation or exceeds the permitted use, you will need to obtain permission directly from the copyright holder. To view a copy of this licence, visit http://creativecommons.org/licenses/by/4.0/.

\section{References}

1. Siegel RL, Miller KD, Jemal A (2015) Cancer statistics, 2015. CA Cancer J Clin 65:5-29

2. Raffone A, Travaglino A, Mascolo M, Carbone L, Guida M, Insabato L, Zullo F (2019) TCGA molecular groups of endometrial cancer: Pooled data about prognosis. Gynecol Oncol 155(2):374-383

3. Concin N, Matias-Guiu X, Vergote I et al (2021) ESGO/ESTRO/ ESP guidelines for the management of patients with endometrial carcinoma. Int J Gynecol Cancer 31(1):12-39

4. Cancer Genome Atlas Research Network, Kandoth C, Schultz N, Cherniack AD, Akbani R, Liu Y et al (2013) Integrated genomic characterization of endometrial carcinoma. Nature 497:67-73

5. Stelloo E, Bosse T, Nout RA et al (2015) Refining prognosis and identifying targetable pathways for high-risk endometrial cancer; a TransPORTEC initiative. Mod Pathol 28(6):836-844

6. Kim SR, Cloutier BT, Leung S et al (2020) Molecular subtypes of clear cell carcinoma of the endometrium: opportunities for prognostic and predictive stratification. Gynecol Oncol 158(1):3-11

7. Joehlin-Price A, Van Ziffle J, Hills NK, Ladwig N, Rabban JT, Garg K (2020) Molecularly classified uterine FIGO Grade 3 endometrioid carcinomas show distinctive clinical outcomes but overlapping morphologic features. Am J Surg Pathol 45(3):421-429

8. Conlon N, Da Cruz PA, Ashley CW et al (2020) Endometrial carcinomas with a "Serous" component in young women are enriched for dna mismatch repair deficiency, lynch syndrome, and POLE exonuclease domain mutations. Am J Surg Pathol 44(5):641-648

9. Bosse T, Nout RA, McAlpine J et al (2018) Molecular classification of Grade 3 endometrioid endometrial cancers identifies distinct prognostic subgroups. Am J Surg Pathol 42(5):561-568

10. DeLair DF, Burke KA, Selenica P et al (2017) The genetic landscape of endometrial clear cell carcinomas. J Pathol 243(2):230-241

11. Raffone A, Travaglino A, Mascolo M et al (2020) Histopathological characterization of ProMisE molecular groups of endometrial cancer. Gynecol Oncol 157(1):252-259 
12. Myers A, Barry WT, Hirsch MS, Matulonis U, Lee L (2014) $\beta$-Catenin mutations in recurrent FIGO IA grade I endometrioid endometrial cancers. Gynecol Oncol 134(2):426-427

13. Stelloo E, Nout RA, Osse EM et al (2016) Improved risk assessment by integrating molecular and clinicopathological factors in early-stage endometrial cancer-combined analysis of the PORTEC cohorts. Clin Cancer Res 22(16):4215-4224

14. Kurnit KC, Kim GN, Fellman BM et al (2017) CTNNB1 (betacatenin) mutation identifies low grade, early stage endometrial cancer patients at increased risk of recurrence. Mod Pathol 30(7):1032-1041

15. Moroney MR, Davies KD, Wilberger AC et al (2019) Molecular markers in recurrent stage I, grade 1 endometrioid endometrial cancers. Gynecol Oncol 153(3):517-520

16. Li Y, Li J, Guo E et al (2020) Integrating pathology, chromosomal instability and mutations for risk stratification in early-stage endometrioid endometrial carcinoma. Cell Biosci 22(10):122

17. Imboden S, Tapia C, Scheiwiller N, Kocbek V, Altermatt HJ, Janzen J, Mueller MD, McKinnon B (2020) Early-stage endometrial cancer, CTNNB1 mutations, and the relation between lymphovascular space invasion and recurrence. Acta Obstet Gynecol Scand 99(2): 196-203

18. Stasenko M, Feit N, Lee SSK et al (2020) Clinical patterns and genomic profiling of recurrent "ultra-low risk" endometrial cancer. Int J Gynecol Cancer 30(6):717-723

19. Talhouk A, McConechy MK, Leung S et al (2015) A clinically applicable molecular-based classification for endometrial cancers. Br J Cancer 113:299-310

20. Pasanen A, Ahvenainen T, Pellinen T, Vahteristo P, Loukovaara M, Bützow R (2020) PD-L1 expression in endometrial carcinoma cells and intratumoral immune cells: differences across histologic and TCGA-based molecular subgroups. Am J Surg Pathol 44(2):174-181

21. Talhouk A, McConechy MK, Leung S et al (2017) Confirmation of ProMisE: a simple, genomics-based clinical classifier for endometrial cancer. Cancer 123:802-813

22. Kolehmainen AM, Pasanen AM, Koivisto-Korander RL, Bützow RC, Loukovaara MJ (2020) Molecular characterization in the prediction of disease extent in endometrial carcinoma. Eur J Obstet Gynecol Reprod Biol S0301-2115(20):30669-30672

23. Kommoss S, McConechy MK, Kommoss F et al (2018) Final validation of the ProMisE molecular classifier for endometrial carcinoma in a large population-based case series. Ann Oncol 1(29):1180-1188

24. Rau TT, Bettschen E, Büchi C, Christe L, Rohner A, Müller MD, Carlson JW, Imboden S, Zlobec I (2020) Prognostic impact of tumor budding in endometrial carcinoma within distinct molecular subgroups. Mod Pathol. https://doi.org/10.1038/s41379-0200626-9 (Epub ahead of print)

25. Travaglino A, Raffone A, Gencarelli A et al (2020) Clinicopathological features associated with mismatch repair deficiency in endometrial undifferentiated/dedifferentiated carcinoma: a systematic review and meta-analysis. Gynecol Oncol S0090-8258(20):34126-34133

26. Moher D, Shamseer L, Clarke M et al (2015) Preferred reporting items for systematic review and meta-analysis protocols (PRISMA-P) 2015 statement. Syst Rev 4:1

27. Travaglino A, Raffone A, Mascolo M et al (2020) TCGA molecular subgroups in endometrial undifferentiated/dedifferentiated carcinoma. Pathol Oncol Res 26(3):1411-1416

28. Whiting PF, Rutjes AW, Westwood ME et al (2011) QUADAS-2: a revised tool for the quality assessment of diagnostic accuracy studies. Ann Intern Med 155(8):529-536

29. Travaglino A, Raffone A, Saccone G et al (2019) Nuclear expression of $\beta$-catenin in endometrial hyperplasia as marker of premalignancy. APMIS 127(11):699-709
30. Travaglino A, Raffone A, Saccone G, De Luca C, Mollo A, Mascolo $\mathrm{M}$ et al (2019) Immunohistochemical nuclear expression of $\beta$-catenin as a surrogate of CTNNB1 exon 3 mutation in endometrial cancer. Am J Clin Pathol 2(151):529-538

31. Travaglino A, Raffone A, Saccone G et al (2020) Immunophenotype of atypical polypoid adenomyoma of the uterus: diagnostic value and insight on pathogenesis. Appl Immunohistochem Mol Morphol 28(8):646-653

32. Travaglino A, Raffone A, Stradella C et al (2020) Impact of endometrial carcinoma histotype on the prognostic value of the TCGA molecular subgroups. Arch Gynecol Obstet 301(6):1355-1363

33. Raffone A, Travaglino A, Cerbone $M$ et al (2020) Diagnostic accuracy of immunohistochemistry for mismatch repair proteins as surrogate of microsatellite instability molecular testing in endometrial cancer. Pathol Oncol Res 26(3):1417-1427

34. Catasus L, Matias-Guiu X, Machin P et al (2000) Frameshift mutations at coding mononucleotide repeat microsatellites in endometrial carcinoma with microsatellite instability. Cancer 88(10):2290-2297

35. Raffone A, Travaglino A, Cerbone $\mathrm{M}$ et al (2020) Diagnostic accuracy of p53 immunohistochemistry as surrogate of TP53 sequencing in endometrial cancer. Pathol Res Pract 216(8):153025

36. Kim G, Kurnit KC, Djordjevic B et al (2018) Nuclear $\beta$-catenin localization and mutation of the CTNNB1 gene: a contextdependent association. Mod Pathol 31:1553-1559

37. van den Heerik ASVM, Horeweg N et al (2020) PORTEC-4a: international randomized trial of molecular profile-based adjuvant treatment for women with high-intermediate risk endometrial cancer. Int J Gynecol Cancer 30(12):2002-2007

38. Wortman BG, Astreinidou E, Laman MS et al (2020) Brachytherapy quality assurance in the PORTEC-4a trial for molecularintegrated risk profile guided adjuvant treatment of endometrial cancer. Radiother Oncol 5(155):160-166

39. Wortman BG, Bosse T, Nout RA et al (2018) Molecular-integrated risk profile to determine adjuvant radiotherapy in endometrial cancer: evaluation of the pilot phase of the PORTEC-4a trial. Gynecol Oncol 151(1):69-75

40. Cosgrove CM, Tritchler DL, Cohn DE et al (2018) An NRG Oncology/GOG study of molecular classification for risk prediction in endometrioid endometrial cancer. Gynecol Oncol 148(1):174-180

41. Britton H, Huang L, Lum A et al (2019) Molecular classification defines outcomes and opportunities in young women with endometrial carcinoma. Gynecol Oncol 153(3):487-495

42. Vermij L, Smit V, Nout R, Bosse T (2020) Incorporation of molecular characteristics into endometrial cancer management. Histopathology 76(1):52-63

43. D’Alessandris N, Travaglino A, Santoro A et al (2021) TCGA molecular subgroups of endometrial carcinoma in ovarian endometrioid carcinoma: a quantitative systematic review. Gynecol Oncol 163(2):427-432

44. D'Andrilli G, Masciullo V, Bagella L et al (2004) Frequent loss of $\mathrm{pRb} 2 / \mathrm{p} 130$ in human ovarian carcinoma. Clin Cancer Res 10(9):3098-3103

45. Petrillo M, Zannoni GF, Beltrame L et al (2016) Identification of high-grade serous ovarian cancer miRNA species associated with survival and drug response in patients receiving neoadjuvant chemotherapy: a retrospective longitudinal analysis using matched tumor biopsies. Ann Oncol 27(4):625-634

46. Ciucci A, Zannoni GF, Travaglia D, Petrillo M, Scambia G, Gallo D (2014) Prognostic significance of the estrogen receptor beta $(E R \beta)$ isoforms $E R \beta 1, E R \beta 2$, and $E R \beta 5$ in advanced serous ovarian cancer. Gynecol Oncol 132(2):351-359

47. Ciucci A, De Stefano I, Vellone VG et al (2013) Expression of the glioma-associated oncogene homolog 1 (gli1) in advanced serous 
ovarian cancer is associated with unfavorable overall survival.

PLoS ONE 8(3):e60145

Publisher's Note Springer Nature remains neutral with regard to jurisdictional claims in published maps and institutional affiliations. 